\title{
Organizational Structure And Standard Development Procedures Of standard Development Organizations-Comparative Research Based On Domestic And Foreign Perspectives
}

\author{
Zhu Xianghua \\ China National Institute of Standardization, Beijing, China
}

\begin{abstract}
This paper takes the typical foreign standard development organizations IEEE, ASTM, W3C, and IETF as examples to analyze the characteristics of organizational structure and standard developing procedures. These four organizations are typical representative of foreign SDOs which can be divided into two categories, one is represented by IEEE and ASTM which are legal entities and their standardization organization structure and standard development procedures are relatively fixed. The other is represented by W3C and IETF, which are relatively loose and open and their standardization organizations and standard development process are more flexible. At the same time, this paper also selects the top ten social organizations that are active on the Chinese national information platform of social organization standard. Compared with foreign social organizations, it is found that their standardization organization structures are not transparent enough and too concentrated. It also found that the standard development process of Chinese social organization is relatively simple and lack of innovation.
\end{abstract}

\section{Organizational structure and standard development procedures of foreign standard development organizations}

\subsection{Case studies abroad}

\subsubsection{Organizational structure and standard development procedures of IEEE.}

IEEE (Institute of Electrical and Electronics Engineers) is the world's largest technical professional organization for the advancement of technology with an active portfolio of nearly 1,300 standards $^{[1]}$.

\subsubsection{Organizational structure of IEEE}

Established and appointed by the IEEE SA (standard association) Board of Governors (BOG) the IEEE SA Standards Board encourages and coordinates the development and revision of IEEE standards. The SASB gives final approval to IEEE standards prior to publication and processes all necessary appeals. There are some committees under IEEE SA, which are Audit Committee (AudCom), New Standards Committee (NesCom), Patent Committee (PatCom), Procedures
Committee (ProCom), Standard Review Committee (RevCom) and Industry Connections Committee (ICCCom).

\subsubsection{2. standard development procedure of IEEE}

The process of IEEE Standards development includes initiating the project, mobilizing the, gaining final approval and maintaing the standard.

\subsubsection{Interaction between IEEE standardization organization and process}

During the procedure of IEEE standards there are different department play roles in it. Working groups draft the standards. IEEE AS manages and coordinates the standardization work. NesCom review the new proposal item and RevCom review the final draft. IEEE SASB approvals IEEE standards. There are also AudCom, PatCom andProCom work together to ensure IEEE standards will follow IEEE's requirements which is listed as Figure I.

\subsubsection{Organizational structure and standard development procedures of ASTM.}

ASTM (American Society for Testing and Materials) has published over 12,000 ASTM standards operate globally ${ }^{[2]}$.

zhuxh@enis.ac.cn 


\subsubsection{Organizational structure of ASME}

There are Board Committees \& Standard Committees in ASTM. Board Committees consist of Executive Committee and Finance and Audit Committee. Standard Committees consist of Committee on Standard, Committee on Publications and Committee on Technical Committee Operations. There are eight President or Vice President who are in charge of a working field which includes Laboratory Services \& Certification, Global Cooperation, Global Policy and Communications, Business Development, Finance and Treasure, etc. These eight departments are in charged by president who is also the member of Board of Director.

\subsubsection{2 standard development procedure of ASME}

The ASTM standard development process mainly includes the following stages, which are suggestions, proposal, standard drafting, subcommittee balloting, main committee balloting, standards committee approval, approval and release $\mathrm{e}^{[3]}$.

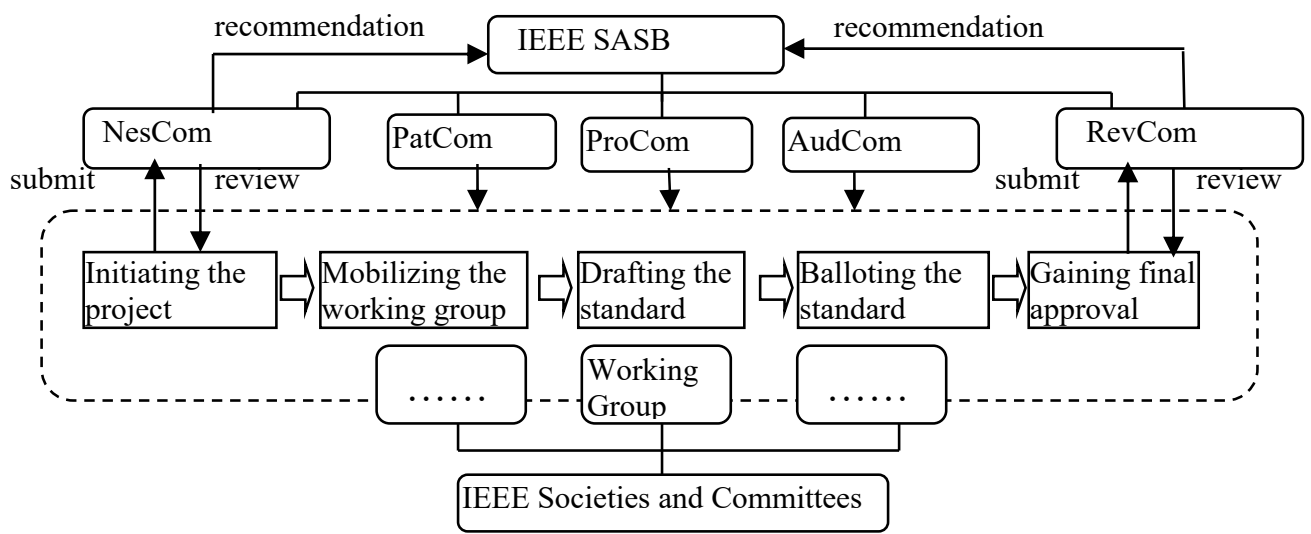

Figure I. Interaction between IEEE standardization organization and process

\subsubsection{Interaction between IEEE standardization organization and process}

In ASTM the approval of ASTM standard item suggestion shall be decided by vote of the sub-technical committee. Working group will draft the standards. After the standard is drafted, there will vote in both subcommittee and main committee. Then COS determines that the procedural requirements of the Society have been satisfied and the standard will be published by ASTM. Cooperation of various institutions during the development of ASTM standards are listed as Figure II.

\subsubsection{Organizational structure and standard development procedures of W3C.}

The World Wide Web Consortium (W3C) is an international community that develops open standards to ensure the long-term growth of the Web, led by Web inventor and Director Tim Berners-Lee and CEO Jeffrey Jaffe. W3C does not have a single physical headquarters. There are four institutions, however, that "host" W3C ${ }^{[4]}$.

\subsubsection{Organizational structure of $W 3 C$}

W3C Member organizations provide resources to this end, and the W3C Team provides the technical leadership and organization to coordinate the effort. The
Advisory Committee is composed of one representative from each Member organization. Employees of Member organizations participate in Working Groups, Interest Groups, and Coordination Groups and author and review documents on the Recommendation track. The Team consists of the W3C paid staff and W3C Fellows. It is led by the Chairman and the Director.

\subsubsection{2. standard development procedure of W3C}

The procedure of W3C's recommendation consists of six stages, which are Working Draft, Candidate Recommendation, Proposed Recommendation, W3C Recommendation.

\subsubsection{Interaction between W3C standardization organization and process}

W3C's recommendations are developed in a way that is similar to the standard development process of a traditional standards organization, which should be gained consensus at each maturity levels. But unlike the traditional standards develop process the W3C's is more flexible. During the development of W3C recommendations, if Working Groups or Advisory Committees recommend that standards require further review or modification, the process may even return to the previous stage, which is listed as Figure $\mathrm{III}^{[4]}$. 


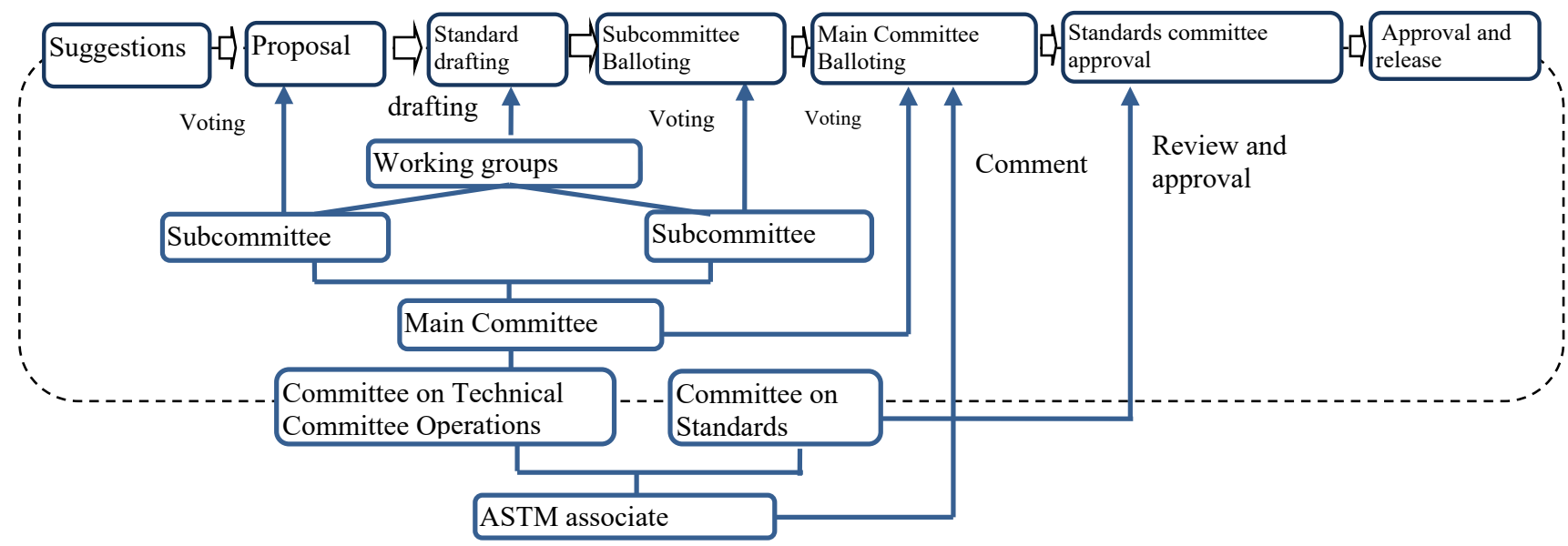

FigureII. Interaction between IEEE standardization organization and process

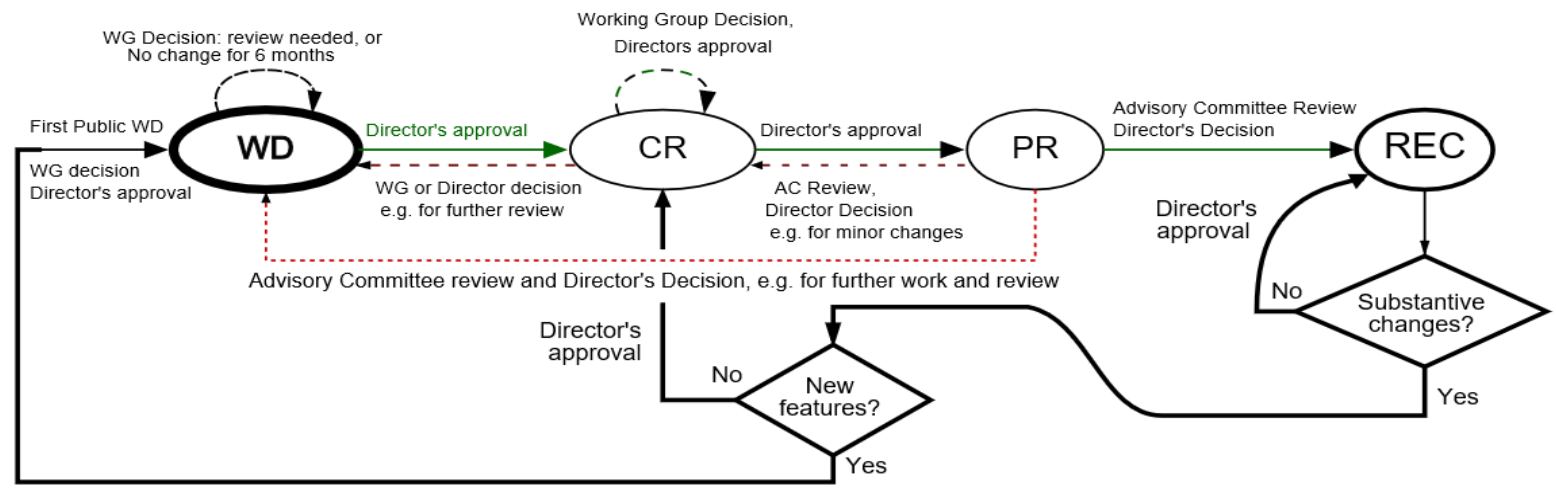

Figure III. Interaction between W3C standardization organization and process

\subsubsection{Organizational structure and standard development procedures of IETF.}

The Internet Engineering Task Force (IETF) is a large open international community of network designers, operators, vendors, and researchers concerned with the evolution of the Internet architecture and the smooth operation of the Internet. It is open to any interested individual ${ }^{[5]}$. The interaction between IETF standardization organization and process is as Figure $\mathrm{IV}^{[6]}$.

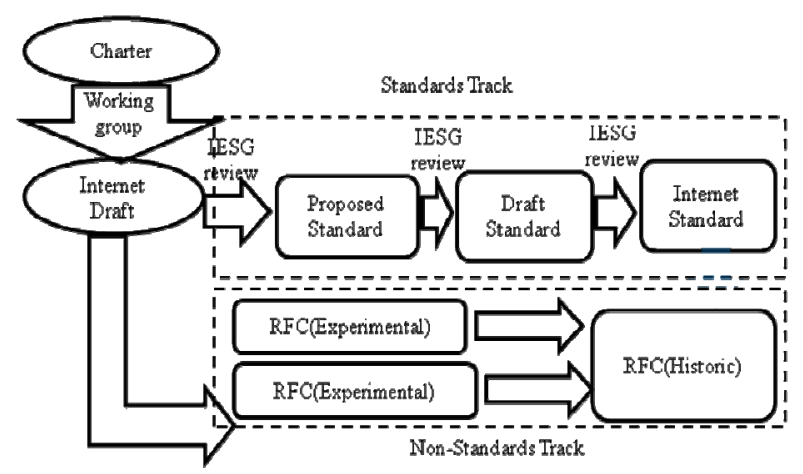

Figure IV. Interaction between IETF standardization organization and process

\subsubsection{Organizational structure of IETF}

The technical work of the IETF is done in Working Groups, which are organized by topic into several Areas. Much of the work is handled via mailing lists. The IETF working groups are grouped into areas, and managed by Area Directors, or ADs. The ADs are members of the Internet Engineering Steering Group (IESG). Providing architectural oversight is the Internet Architecture Board, (IAB). The IAB and IESG are chartered by the Internet Society (ISOC) for these purposes. ${ }^{[5]}$. 


\subsubsection{2. standard development procedure of $W 3 C$}

Each distinct version of an Internet standards-related specification is published as part of the "Request for Comments" (RFC) document series. Some RFCs document are Internet Standards. Specifications that are intended to become Internet Standards evolve through a set of maturity levels known as the "standards track", which are Proposed Standard, Draft Standard and Internet Standard.

\subsubsection{Interaction between W3C standardization organization and process}

Most of IETF's standardization work is done on email lists. In the process of IETF' standard track, with the change of practice, the stages of different maturity levels will be constantly discussed and modified, and the whole standard may be overturned and restarted.

\subsection{The characteristics of standardization organization structure and standard development procedure of foreign SDOs}

IEEE, ASTM, W3C and IETF, as the typical social groups in the world, actually represent the characteristics and development trend of the two kinds of social organizations. One is the legal entity social group represented by IEEE and ASTM, which work in the traditional field. The other is an open and loose social organizations represented by $\mathrm{W} 3 \mathrm{C}$ and IETF, which work in the Internet field. IEEE, ASTM, W3C, and IETF all have specialized standardization organization structure and standard development procedures. But their standardization organization structure and standardsetting procedures are different. Comparison of the two types of SDOs is listed in Table I.

Table I. Comparison of the two types of SDOs

\begin{tabular}{|l|l|l|}
\hline $\begin{array}{l}\text { standardization } \\
\text { organization } \\
\text { structure }\end{array}$ & $\begin{array}{l}\text { IEEE, ASTM } \\
\text { The hierarchy } \\
\text { with multiple } \\
\text { levels }\end{array}$ & $\begin{array}{l}\text { Flat } \\
\text { organizational } \\
\text { structure }\end{array}$ \\
\hline $\begin{array}{l}\text { Standard } \\
\text { development } \\
\text { procedure }\end{array}$ & $\begin{array}{l}\text { One-way } \\
\text { propulsion }\end{array}$ & $\begin{array}{l}\text { Multidirectional } \\
\text { propulsion }\end{array}$ \\
\hline Working pattern & $\begin{array}{l}\text { Work face to } \\
\text { face }\end{array}$ & $\begin{array}{l}\text { Internet, email } \\
\text { communication }\end{array}$ \\
\hline $\begin{array}{l}\text { The structure of } \\
\text { the organization }\end{array}$ & $\begin{array}{l}\text { Tight } \\
\text { organizational } \\
\text { structure }\end{array}$ & $\begin{array}{l}\text { Loose } \\
\text { organizational } \\
\text { structure. } \\
\text { Sometimes no } \\
\text { formal } \\
\text { membership, no } \\
\text { physical } \\
\text { headquarter }\end{array}$ \\
\hline
\end{tabular}

\subsubsection{The characteristics of standardization organization structure}

IEEE and ASTM generally have fixed standard development departments, may be named Technical committee or technology association which work in a special filed. These technical committee or technology association consists of several subcommittees. And subcommittee consists of a number of working groups which develop standards.

On the other hand, W3C and IETF standardization organizations structure are flatter and generally have a large number of working groups which have their own charters to manage the standardization job. Due to the openness of the Internet, membership of such organizations is more flexible. There is even no formal membership in IETF and no physical headquarter W3C. In IETF anyone can register and attend any meeting. In IETF Working Groups are typically created with a charter that describes the specific problem or deliverables (a guideline, standards specification, etc.)

\subsubsection{Characteristics of standard development procedures}

The standard development process of IEEE and ASTM is relatively stable, and are one-way propulsion. Standard item can be pushed to a higher stage after reaching consensus according to the established procedure requirements.

The $\mathrm{W} 3 \mathrm{C}$ and IETF have a more flexible standards development process, probably because both of them work in the field of Internet where there are more open, loose and flexible. During its standard development process, the communications are often carried out on Internet or email. In these SDOs, even if the standard item has advanced to a higher level, it can still be return back to a former status when the requirement is not satisfied.

\section{The present situation of social organizations in China}

By the end of December 31, 2019, the top ten social organizations registered in the National Social Organization Standards Information Platform are: Zhejiang Brand Construction Federation, Shenyang Citizens' Education Association, Zhongguancun Material Testing Technology Alliance, and China Standardization Association , Zhejiang Provincial Product and Engineering Standardization Association, China Electrical Equipment Industry Association, Commercial Industry Committee of China Council for the Promotion of International Trade, China Engineering Construction Standardization Association, China Association of Chinese Medicine, Shandong Standardization Association $^{[7]}$. 


\section{1 status of standardization orgnaniztion}

\subsection{1 standardization organization is lack of Transparency}

Foreign social organizations own their own official websites, on which they publish detailed information on their standardization work to ensure that their work is open and transparent. In terms of ten social organizations in China, six social organizations have official websites, on which information related standardization work is disclosed. The four social organizations without official websites are: Shenyang Citizens' Education Association, ZhongGuancun Material Testing Technology Alliance, Zhejiang Product and Engineering Standardization Association, and Standardization Association of Shandong. It concludes that the social organizations registered with the Ministry of Civil Affairs of the State Council are relatively more orderly and transparent, which can be seen from the fact that they have established their own official websites and disclosed relevant information on them. But the transparency and normativity of local social organizations need to be improved.

Even for the above-mentioned social organizations that have established official websites, the various regulations of standardized work opened on their official websites are still not very detailed and comprehensive, which mainly manifested in the lack of soundness of the operation mechanism of the standardized management of social organizations, the simplified standard-setting procedure and poor operability of standards, and incomplete organizations of standardization and working mechanisms, etc ${ }^{[8] 9]}$.

\subsubsection{Standardization organization structures is concentrated}

From the perspective of these 10 social organizations, there is a standardization administration department within each social organization, although the name of these departments may be different, which may be standardization committee/standardization work committee/standardization management committee/technical standards department, etc. However, under these departments, there is no special branch according to specific work. In fact, standardization work involves procedures, intellectual property rights, appeal, etc. Each needs a different background of knowledge and expertise. All the work is concentrated at one department, which will lead to chaos and unprofessional work $^{[10]}$.

On the one hand, the untransparent of the Standardization organization structure is due to the lack of working principles and methods of standardization by social organizations which leads to an imperfect structure of their standardization organizations ${ }^{[1]}$.

\subsubsection{The management level of standardization is low}

In these 10 social groups, there is a standardization management department within each social organization. However, these departments are not professional in the management of standardization work, which is reflected in the fact that the main responsibility of these departments is to approval the proposal and review of the standard items. It is obvious that the working mechanism of these departments is too simple ${ }^{[12]}$.

The low management level of standardization management organizations indicates that the level of social organizations standardization in China is low and the management ability is not high.

\section{2 status of standard development procedure}

\subsubsection{The standard development procedure is relatively simple}

In term of the standard development procedure documents of these 10 social organizations it is obvious that the procedures are relatively simple, most of which are principled provisions on the development process and lack of practical details requirements. Most of the requirements that should be met when the standard is promoted from low-level stage to high-level stage are voting requirement, lack of requirements on technology and maturity, insufficient clarity on the membership, etc.

\subsubsection{The standard development procedure is lack of innovation}

According to the standard development procedures of these 10 social organizations, they basically follow the process of project proposal, drafting, common comment, technical review, approval, publication and review. These procedures are similar to those of a formal standards development organization. Actually social organization standards are often oriented to the rapid change of market demands and innovation that social organizations in some innovative could try to set up more flexible procedure of standard development.

\section{Conclusion}

Standardization organization structure and standard development procedure are important mechanisms to carry out standardization work. From the domestic and foreign cases, there is no two social organizations with the same standardization organizations structure and standard development procedure. However, the principles of openness, transparency and fairness should be met no matter how the standardization organizations structure and standard development procedure are set. Due to its long development history, there are several social organizations with international influence abroad. Those foreign social organizations work in different ways to meet their different development requirements. 
Throughout China, due to the short development course most social organizations are lack of standardization work experience. The standardization organization structure is concentrated and low management level. The standard development procedure is relatively simple and the procedure pattern is single and lacks the innovation.

\section{REFERENCES}

1. https://www.iee.org/content/dam/ieeeorg/ieee/web/org/about/organization_summary.pdf

2. www.astm.org

3. ASTM, Regulations Governing ASTM Technical Committees, Oct,2019

4. http://www.w3.org/2019/Process-20190301/

5. https://www.ietf.org

6. Xu Qing, Analysis of IETF Association Standards Developing Policy and Its Enlightenment, STANDARD SCIENCE, 2018, No.8,p:44-51.

7. www.ttbz.orc.cn

8. GB /T 20003.1 Social Organization Standardization Part 1: Guidelines for Good practice

9. Zhu Xianghua, Wang Yiyi, Xu Qing, et. Guidelines and Practices for Good Practice in Social Organization Standardization, Standards Press of China, December 2018.

10. Zhu Xianghua, Copyright of Social Organization Standards and the Design of Copyright System of Social Organization Standards from the Perspective of Copyright Law, Standard Science, 2018.08, P: 32-38.

11. China National Institute of Standardization, Research Report of Development of Social Organization Standardization, Standards Press of China, December 2018.

12. Zhu Xianghua, Analysis on Supervision of Social Organizations Standardization , Standard Science, 2019.01, P: 15-0-155. 